\title{
Quando os pais precisam de psicoterapia mas encaminham seus filhos, o que fazer?
}

\author{
Cynthia Borges de Moura e Renata Grossi \\ Universidade Estadual de Londrina
}

Esta comunicação tem por objetivo discutir e analisar alguns fatores que fazem com que pais freqüentemente mães - encaminhem seus filhos para terapia, como um pretexto para a sua própria terapia pessoal. Situando o problema de outro modo, tentaremos discutir situações clínicas nas quais crianças são trazidas para terapia com queixas inespecíficas, ou com queixas não observadas pelos terapeutas durante a avaliação, mas cujos pais insistem no acompanhamento psicoterápico, uma vez que eles também recebem acompanhamento paralelo periodicamente, e nestes momentos, podem tratar de seus problemas pessoais.

Identificar estas situações e os fatores em comum entre estes casos com certeza facilita ao terapeuta a condução adequada do processo psicoterapêutico no sentido de in- verter o encaminhamento e levar os próprios pais a procurarem ajuda e enfrentarem seus problemas pessoais ej ou conjugais sem a mediação do filho. Deste modo, as crianças encaminhadas são poupadas de

Endereço para correspondência com o Editor: Universidade Estadual de Londrina, Campus Universitário, Centro de Ciências Biológicas, Depto. de Psicologia Geral e Análise do Comportamento, Cx Postal 6001, CEP 86051-990, Londrina, PR. E-mail: cynthia@npd.uel.br. Fone: (043) 371-4227 Fax: (043) 371-4207

Agradecemos a colaboração das alunas Silvia E.Gabassi e Karina G. Silva que atuaram como terapeutas dos casos aqui relatados. serem tidas como "problemas", pois os pais reconhecem que sua percepção acerca de seu filho está mais sob controle de seus próprios desajustes do que do comporta- mento do filho - que em muitos casos pode estar apropriado ao nível de desenvolvi- mento da criança.

\section{Avaliando a criança, os pais ou o problema?}

Segundo Wells (1981), o encaminha- mento da criança para terapia pode decorrer mais de uma necessidade da família ou pais, do que da própria criança. Muitas pesquisas têm demonstrado que outros fa- tores além do próprio comportamento da criança parecem contribuir para a percepção que os pais têm sobre eles (Shepherd, Oppenheim e Mictchell, 1966; Griest, Forehand, Wells e McMahon, 1980). Os pais costumam reclamar que não sabem quais comportamentos esperar de seus filhos nos diversos momentos do desenvolvimento destes (Marinho, 1994), o que acentua a dificuldade em perceber seu filho como não problemático. Eles também podem perceber suas crianças como problemáticas ou desadaptadas embora comportamental- mente não se encontre diferença entre as crianças encaminhadas para auxílio psicológico e as não encaminhadas (Marinho e Silvares, 1996). Cynthia Borges de Moura 
Segundo Ross (1979), a interação entre o comportamento da criança e a tolerância dos adultos significativos de seu ambiente é um dos fatores responsáveis pela percepção de padrões anormais de comportamento. Os pais podem ter baixa tolerância para comportamentos que são altamente desorganizados e desagradáveis (como no caso de comportamento agressivo ou opositor) e rapidamente queixam-se quando esses comportamentos ocorrem. Por outro lado reações que não os incomodam (como ansiedade ou fobias) podem ser toleradas mais facilmente. Em geral, conforme apontam Bee (1984) e Rheingold (1969) muito do que os pais consideram como comportamento inapropriado de suas crianças pode estar perfeitamente adequado e esperado para o nível de desenvolvimento da criança.

Muitos fatores contribuem para uma percepção parental negativa sobre a criança e conseqüente encaminhamento. Griest, Forehand, Wells e McMahon (1980) apontam quatro fatores que têm sido estudados: a) o comportamento da criança; b) o comportamento dos pais; c) as percepções dos pais sobre o comportamento da criança e; d) o ajustamento pessoal e conjugal dos pais. Alguns estudos que investigaram esses fatores apontam que mães de crianças encaminhadas vivenciaram problemas emocionais variados, apresentam baixa tolerância ao estresse e pouca habilidade para lidar com suas crianças do que mães de crianças não encaminhadas. Outros ainda apontam a depressão materna como o melhor preditor da percepção distorcida da mãe sobre o comportamento do filho. A percepção de mães de crianças não encaminhadas sobre o ajustamento de seus filhos normalmente baseia-se mais no próprio comportamento atual da criança. Isso sugere que em famílias normais há uma relação direta entre o comportamento da criança e a percepção dos pais sobre seu comporta- mento, enquanto que em famílias com distúrbios de conduta a percepção dos pais sobre a criança é influenciada pela interação de dois fatores: o comportamento da criança e o ajustamento emocional dos pais.

Marinho e Silvares (1996), estudando essa questão, perceberam que os pais com mais filhos (três ou mais) são mais hábeis em resolver os conflitos com as crianças do que aqueles que possuem menos filhos (um ou dois), porém o número de filhos não é uma contingência que determina o encaminhamento ou não da criança. Em uma avaliação comportamental, tanto os pais com mais como com menos filhos tendem a não considerar a necessidade de atendimento psicoterápico para seus filhos quando os avaliam globalmente, mas quando respondem às questões pontuais de um questionário como o CBCL de Achembach (1991) acabam por indicar tal necessidade.

Outros fatores extracriança, segundo Wells (1981), podem influenciar a percepção dos pais e o encaminhamento da criança para terapia, entre eles está a qualidade do relacionamento conjugal. Johnson e Lobitz (1974, apud Wells, 1981) encontraram em um estudo uma significante correlação entre insatisfação conjugal e uma percepção negativa dos pais em relação ao comportamento da criança. Quando os pais precisam de psicoterapia mas encaminham seus filhos, o que fazer? 71

Considerando esses fatores, Wells (1981) afirma que a população clínica infantil que procura atendimento pode ser dividida em três grupos:

1) Crianças comportamental e emocional- mente problemáticas cujas percepções dos pais estão baseadas no próprio comporta- mento da criança;

2) Crianças problemáticas cujas percepções dos pais são também influenciadas por seu próprio mal ajustamento pessoal; 3) Crianças relativamente normais cujas percepções dos pais não são adequadas e 
estão baseadas em seu mal ajustamento pessoal, baixa tolerância ao estresse ou alto nível de aceitabilidade, mais do que sobre o comportamento atual da criança.

O primeiro grupo classificado por Wells refere-se àquela população infantil que realmente precisa de atendimento psicológico e cuja avaliação normalmente corrobora e cOlnplelnenta as informações fornecidas pelos pais. Nestes casos, a própria criança pode ser atendida $e j$ ou seus pais orientados para que os problemas apresentados sejam solucionados.

O segundo e terceiro grupos se constituem em análises à parte. A avaliação normalmente é mais complexa e a forma de condução de tais casos é menos clara para o terapeuta. São esses casos que necessitam de uma avaliação criteriosa para que os fatores diferenciais sejam identificados e o tratamento seja direcionado para o elemento da família que realmente precisa dele.

A seguir descreveremos dois casos atendidos na Clínica Psicológica da Universidade Estadual de Londrina e que ilustram esses dois últimos grupos de clientes. O objetivo desta análise é discutir como OS

fatores apontados podem ser detectados e conduzidos adequadamente na prática clínica. Vale ressaltar que os casos aqui apresentados não foram selecionados em função de características especiais que facilitaram o diagnóstico diferencial e o encaminhamento adequado. Pelo contrário, os casos aqui analisados são representativos de situações clínicas similares que têm freqüientemente ocorrido neste contexto de Clínica-Escola e que têm justificado a condução de intervenções terapêuticas nos mesmos moldes das que serão descritas abaixo.

O primeiro caso - que se encaixa no segundo grupo - ilustra como uma dificuldade específica da criança pode ser acentuada por uma percepção distorcida dos pais, a qual maximiza a intensidade do problema e conseqüentemente altera o nível de auxílio necessário à criança. O segundo caso - que se encaixa no terceiro grupo - mostra como os pais podem trazer a criança que não apresenta desvios de comportamento, queixando-se de um problema inespecífico e não existente, que faz com que o foco seja transferido para a terapia da mãe, a qual realmente apresentava problemas que justificavam um acompanhamento psicoterápico.

\section{Ilustrando a conduta do terapeuta com alguns casos}

O primeiro caso atendido foi de uma criança de 11 anos, do sexo masculino, de nível socioeconômico médio e filho do meio. Foi encaminhada pelos pais para psicoterapia com queixa de ser muito teimoso e desobediente. A mãe relata que «quando ele não se interessa por algo não faz e quando se interessa não larga enquanto não ter- mina. Isso traz conseqüências na escola onde as professoras não estão tendo paciência em relação às atividades que ele se recusa a fazer". A mãe diz ainda que a criança não respeita horários, em alguns momentos não aceita as coisas que a mãe faz para ela e em outros requisita a atenção da mãe, até mesmo para ajudá-Ia a se vestir. A criança possuía história de tratamento psicológico, tendo passado por quatro episódios anteriores de atendimento no mesmo local.

Desde a primeira avaliação a criança foi encaminhada para tratamento psicopedagógico, por terem sido detectados problemas de aprendizagem e não problemas comportamentais relevantes que justificas- sem a psicoterapia. A mãe concordou com o encaminhamento, chegou a procurar uma avaliação psicopedagógica para o filho, a qual não levou adiante, e insistia na continuidade do 
atendimento psicoterápico. Devido à constante solicitação da mãe, a criança foi atendida pela terapeuta que continuava investigando as queixas e não observando os problemas relatados. Paralelamente a isso, nas sessões de orientação aos pais, a mãe comparecia e discutia com a terapeuta seus próprios problemas pessoais e conjugais, abordando apenas em poucos mo- mentos a questão dos "problemas do filho".

Levantou-se a hipótese de que a mãe poderia estar procurando o atendimento para o filho como forma de manter um vínculo com a terapeuta e poder dessa forma justificar seu comparecimento à terapia, momento em que discutia seus problemas conjugais e insatisfações pessoais. Por outro lado, o filho encaminhado parecia re-

querer cuidados corriqueiros por parte da mãe, a qual parecia estar pouco sensível a tais exigências (como demonstrações de afetividade e atenção), provavelmente em função do enfrentamento de suas questões pessoais. Desta forma a criança intensificava a emissão de alguns comportamentos (brincava com fogo, atrasava-se para os compromissos, contrariava as idéias da mãe, e opunha-se à maioria dos comporta- mentos esperados por ela), pois apenas reações intensas de sua parte tinham como consequiência uma atenção mínima (mesmo que punitiva) por parte da mãe, pois o pai não percebia o comportamento do filho como inadequado.

Sob o controle dessa hipótese (que dado o padrão que vinha se repetindo parecia a mais provável), a terapeuta continuou atendendo a criança enquanto aguardava vaga para avaliação psicopedagógica no mesmo local e começou a realizar sessões mais freqüentes com a mãe, avaliando a necessidade de sua própria terapia pessoal. A terapeuta analisou com a mãe o quanto as características e preferências de cada filho requeriam dela mais sensibilidade e disponibilidade emocional para lidar com elas, e o quanto seus problemas pessoais a impediam de responder adequada- mente a eles, principalmente ao filho encaminhado. A mãe demonstrou perceber a relação de seu comportamento com o do filho e concordou com o término da terapia da criança, encaminhando-a para o atendimento psicopedagógico e iniciando seu próprio processo de terapia pessoal.

O segundo caso atendido foi de uma criança de 6 anos, do sexo feminino, encaminhada pela mãe para psicoterapia com

Quando os pais precisam de psicoterapia mas encaminham seus filhos, o que fazer? 73

queixa de "racismo". A fanúlia era de nível socioeconômico baixo, de raça negra e a cliente era filha única de mãe solteira. A mãe na primeira entrevista trouxe a queixa de que a criança estava sendo discriminada na escola pela cor de sua pele, estava tendo reações emocionais e verbalizando auto rejeição por causa de sua cor. Quando a terapeuta começou a investigar tal queixa, a mãe não sabia acrescentar dados relevantes. Paralelo a isso relatou dois episódios recentes de perda, o rompimento de seu relacionamento com seu último companheiro e a morte de seu pai (avô da criança). Segundo a mãe, a criança estaria" sofrendo" muito com esses acontecimentos.

Durante as sessões, a terapeuta não observava os comportamentos relatados, a criança apresentava um padrão de espontaneidade, e falava abertamente sobre os assuntos evocados. Com relação ao "racismo", a terapeuta percebeu que a mãe transmitia mensagens indiretas sobre o assunto (alisava o 
cabelo da criança antes de mandá-Ia à escola, entre outras atitudes). Abordando as perdas, a criança relatou: " ... fiquei triste quando o vô morreu porque ele gostava de mim ... tem mais gente que gosta de mim", e sobre o rompimento da mãe com o companheiro falou: " ... eu gostava dele, ele era legal, ... eles brigaram lá, a briga não foi comigo, ele foi embora".

Essas informações obtidas durante as sessões com a criança, associadas às inconsistências no relato da mãe, nos levaram a levantar hipóteses de que a mãe estava apresentando dificuldades em administrar estas questões em sua vida e também em assumir para si mesma a necessidade de auxílio. Por outro lado, a criança estava respondendo às contingências administradas pela mãe em relação à aceitação de si mesma e sua cor, quando a mãe mudou sua atitude, as reações emocionais por parte da criança cessaram. Quanto aos outros acontecimentos, a criança estava tendo uma percepção adequada das situações vivenciadas, as quais não acarretaram prejuízo ao seu desenvolvimento.

Quando a terapeuta começou a discutir essas questões com a mãe, a mesma reconheceu que trazer a filha para atendi- mento psicológico foi de certa forma um modo de facilitar o reconhecimento das dificuldades que enfrentava e a necessidade de auxílio, mesmo que indireto, para si mesma. Foi então realizado o desligamento da criança e o encaminhamento da mãe para sua própria terapia pessoal.

\section{Concluindo: como proceder nesses casos?}

A presente análise evidencia que quando uma criança é encaminhada para tratamento, torna-se igualmente importante avaliar o ajustamento emocional e comportamental dos pais paralelamente à avaliação do problema relatado por eles em relação à criança. Algumas variáveis do contexto familiar e terapêutico assim como alguns padrões comportamentais dos pais devem ser considerados pelo terapeuta diante da suspeita de encaminhamento desnecessário da criança para psicoterapia. A ocorrência dos fatores descritos abaixo, seja qual for a combinação entre eles, pode ser indicativa de que são os pais que necessitam de acompanhamento psicoterápico e devem ser encaminhados:

- Queixa inespecífica e informações vagas sobre o problema atribuído à criança; Cynthia Borges de Moura

- Queixa super valorizada sobre um comportamento que não necessitaria de uma intervenção psicoterapêutica por ser adequado à situação ej ou faixa etária;

- Excesso de disponibilidade ej ou solicitação dos pais para comparecer às sessões;

Avaliação comportamental da criança não correspondente ao relato dos pais (terapeuta, após investigação não observa a ocorrência dos problemas relata- dos);

- Insistência dos pais na psicoterapia da criança quando a avaliação indica que um outro modo de intervenção seria necessário ou suficiente, ou ainda que a psicoterapia não é necessária;

- Pais, durante suas sessões de orientação, falam apenas sobre si mesmos, queixam- se de seus problemas pessoais ou conjugais, e apenas tangenciam o "problema" da criança.

Desta forma, havendo suspeita da ocorrência de uma situação clínica desta natureza, o terapeuta deve coletar informações de múltiplas fontes, como ouvir outras pessoas que convivem com a criança, se possível, realizar observações independentes em locais onde os comportamentos- problema da 
criança supostamente ocorrem (como por exemplo, a escola), avaliar o ajustamento conjugal dos pais, grau de satisfação no casamento e realização pessoal, assim poderá avaliar objetivamente os eventos que controlam o comportamento da criança ej ou dos pais e conduzir adequadamente os processos de intervenção que se fizerem realmente necessários.

Na maioria dos casos, os pais (como já mencionado, freqüentemente, a mãe)

quando detectada a necessidade de sua própria psicoterapia, num primeiro mo- mento, não concordam com tal encaminhamento. Temos observado que é adequado que o terapeuta conduza mais sessões com os pais antes de encaminhá- los, assim poderá discutir tal necessidade com base nos eventos que ocorrerem durante a sessão e que eles próprios trouxerem ej ou relatarem. Esta conduta do terapeuta da criança aumenta a probabilidade de que os pais assumam suas dificuldades pessoais, aceitem o encaminhamento e iniciem seu próprio processo psicoterapêutico, pois são levados a compreender os motivos de tal necessidade e não simples- mente encaminhados à revelia, "porque o terapeuta achou que eles precisam de terapia ou que seria bom fazer" .

Pode-se concluir que a consideração destes fatores sobre a avaliação comporta- mental de crianças tem um impacto evidente, pois o terapeuta deve assumir que a criança encaminhada para tratamento não apresenta necessariamente um distúrbio emocional ou comportamental e que tal percepção, em muitos casos, pode ser de- corrente de problemas emocionais ej ou conjugais dos pais que precisam ser trata- dos. Pais podem levar a criança para a clínica como um pretexto para o tratamento deles mesmos, pois levar a criança para psicoterapia pode ser a maneira mais fácil que eles freqüentemente encontram para ingressar no seu próprio processo psicoterá- pico. Nesses casos, falhas na avaliação de todas as variáveis que contribuem para a percepção do desvio da criança podem resultar em falhas nos encaminhamentos apropriados, impedindo assim que os benefícios de uma psicoterapia bem conduzida e direcionada para os reais problemas apresentados seja usufruída quer pelos pais, filhos ou pela família como um todo.

\section{Referências Bibliográficas}

Achembach, T.M. \& Edelbrock, C.S. (1991). Ma- nual for tne Child Behaoior Checklist and Revised Child Behaoior Profile. Burlington, VT:

University Associates in Psychiatry.

Bee, H. (1984). A criança em desenvolvimento. São Paulo: Harper \& Row.

Griest, D.L., Forehand, R., Wells, K.C. \& Mcmahon, RJ (1980). An examination of differences between nonclinic and behavior problem children clinic-reffered children and their mothers. Journal of Abnormal Psychology, 89, 497-500.

Marinho, M.L. (1994). A clientela infantil da clíni- ca-escola da UEL: análise das queixas e dos procedimentos de encaminhados sob a ótica da prevenção de problemas. Monografia apresen- tada ao Curso de Psicoterapia na Análise do Comportamento, UEL.

Marinho, M.L. \& Silvares, E.F.M. (1996) Solução de conflitos e percepção de ajustamento infantil em pais de 
crianças com e sem encaminhamento psicoterápico. Estudos de Psico- logia, 13, 3, 23-30.

Rheingold, H.L. (1969). O social e a socialização do bebê. In: GOSLIN (Ed.) Handbook of Socia- lization: Teory and Research. (pp. 779-790) Chicago: Rand Mc Nally and Company.

Ross, A.O. (1979) Distúrbios Psicológicos na In- fância. São Paulo: McGraw-Hill.

Shepherd, M.; Oppenheim, A.N. \& Mitchell, S. (1966). Childhood behaviour disorders and the child-guidance clinic: an epidemiological study. [ournal of Child PSYc/1010glj and PSljchiatry, 17,39-52.

Wells, KC. (1981). Assessment of children in outpatient settings. In:HERSEN, M. E BELLACK, A.S. (Eds.) Behavioral Assessment: a practional handbook. New York:

Pergamon Press, 2a. ed., 25-30. 